\title{
USO E EFETIVIDADE DA PAPAÍNA NO PROCESSO DE CICATRIZAÇÃO DE FERIDAS: UMA REVISÃO SISTEMÁTICA
}

\author{
Andréa Pinto LEITEa, Beatriz Guitton Renaud Baptista de OLIVEIRA ${ }^{b}$, \\ Marja Ferreira SOARES ${ }^{c}$, Desirée Lessa Rodrigues BARROCAS ${ }^{\mathrm{d}}$
}

\section{RESUMO}

Trata-se de uma revisão sistemática, cujo objetivo é analisar as evidências sobre o uso da papaína na cicatrização de feridas. Foi realizado levantamento bibliográfico manual e eletrônico nas bases de dados: LILACS; COCHRANE; IBECS; MEDLINE via Pubmed e CINAHL, utilizando os seguintes termos como descritores e como palavras: Carica; Papaína; e Cicatrização, período de 1987 a 2010. Os resultados apontaram predomínio de estudos descritivos, exploratórios, estudos de caso e relatos de caso, apenas um ensaio clínico randomizado e controlado. Os resultados também evidenciaram que a papaína é usada em feridas de diversas etiologias e em todas as fases da cicatrização, sem contraindicações específicas, sendo efetiva e segura, embora haja relatos de ardência e dor. Conclui-se que este estudo contribuiu para demonstrar o uso da papaína nesse período, como fonte de consulta, além de apontar para necessidade de pesquisas com maior rigor metodológico, que proporcionem evidências fortes do seu uso e recomendação.

Descritores: Carica. Papaína. Cicatrização. Cuidados de Enfermagem.

\section{RESUMEN}

Se trata de revisión sistemática, cuyo objetivo es analizar evidencias sobre la papaína en la cicatrización de heridas. Se realizó un levantamiento bibliográfico manual y electrónico en la siguientes bases de datos: LILACS, Cochrane, IBECS, MEDLINE vía PubMed y CINAHL, utilizando los términos como descriptores y también como palabra: Carica (Carica), Papaína (Papain) y Cicatrización de Heridas (Wound Healing), desde 1987 hasta 2010. Los resultados mostraron predominio de estudios descriptivos, exploratorios, estudio de caso e informes de caso, y solamente un ensayo clínico aleatorio y controlado. Los artículos mostraron que la papaina se utiliza en heridas de diversas etiologías y en todas las etapas de la cicatrización; sin contraindicaciones específicas; es efectiva y segura, aunque haya informes de ardor y dolor. Se concluye que este estudio demostró cómo se utiliza la papaína desde 1987 hasta hoy, convirtiéndose en una fuente de consulta y aprendizaje, apuntando la necesidad de búsquedas con más rigor metodológico.

Descriptores: Carica. Papaína. Cicatrización de heridas. Atención de enfermería.

Título: Uso y efectividad de la papaína en la cicatrización de heridas: una revisión sistemática.

\section{ABSTRACT}

This systematic review is aimed at analyzing the evidences about the use of papain in wound healing. A manual and electronic bibliographic research was performed in the following databases: LILACS, Cochrane, IBECS, MEDLINE via Pubmed and CINAHL, using the following terms as descriptors and as word: Carica, Papain and Wound Healing, from 1987 to 2010. The types of studies that predominated were descriptive, exploratory, case studies, case reports and only one randomized controlled clinical trial. The articles showed that papain can be used in wounds of many etiologies and in various healing stages without any specific contraindications, proving to be effective and safe; although there were reports of burning and pain. We conclude that this review contributes to the demonstration of how papain has been used in this period, becoming a learning source, besides pointing to the need of further studies conducted with greater methodological rigor.

Descriptors: Carica. Papain. Wound healing. Nursing care.

Title: Use and effectiveness of papain in the wound healing process: a systematic review.

a Enfermeira. Pós-graduanda do Mestrado Profissional Enfermagem Assistencial da Escola de Enfermagem Aurora de Afonso Costa (EEAAC) - Universidade Federal Fluminense (UFF). Niterói - RJ, Brasil.

b Enfermeira. Pós-doutora. Pesquisadora do CNPq. Professora Titular do Departamento de Fundamentos de Enfermagem e Administração da EEAAC/UFF. Niterói - RJ, Brasil.

c Enfermeira. Residente da EEAAC/UFF. Niterói - RJ, Brasil.

d Acadêmica de Enfermagem do $7^{\circ}$ perídodo da EEAAC/UFF. Niterói - RJ, Brasil. 


\section{INTRODUÇÃO}

Ferida é qualquer interrupção na continuidade de um tecido corpóreo, em maior ou menor extensão, causada principalmente por trauma ou desencadeada por uma afecção clínica. Podem ser agudas e de fácil cicatrização ou crônicas quando ultrapassam seis semanas para cicatrizar, sendo consideradas um problema de saúde pública, devido ao impacto psicológico, social e econômico para o paciente, com elevados e crescentes custos para o sistema de saúde ${ }^{(1)}$, acometendo pessoas independente do sexo, idade ou etnia. A cada dia, diversas tecnologias para tratamento de feridas são lançadas no mercado e um desses produtos é a papaína ${ }^{(2)}$, que provém do látex do mamoeiro Carica papaya, encontrado comumente no Brasil. Trata-se de uma mistura complexa de enzimas proteolíticas e peroxidases, que causam a proteólise, degradação de proteínas em aminoácidos, do tecido desvitalizado e da necrose, sem alterar o tecido sadio, devido a uma antiprotease plasmática - a $\alpha_{1}$-antitripsina, uma globulina humana, presente somente no tecido sadio que inativa as proteases, impedindo a degradação do tecido são ${ }^{(3)}$.

A proteólise é importante, porque a presença de tecido necrótico e de fragmentos celulares na ferida retarda o processo de cicatrização ${ }^{(4)}$. A atividade enzimática da papaína é decorrente de um radical sulfidrila (SH) pertencente ao aminoácido cisteína, por isso, após diluição apresenta odor semelhante ao enxofre ${ }^{(5)}$.

Além de ser usada como desbridante, a papaína possui ação antiinflamatória, atuando na contração e junção de bordos de feridas de cicatrização por segunda intenção ${ }^{(3)}$, podendo ser usada nas diversas fases de cicatrização, com diferentes concentrações de acordo com o tipo de tecido da ferida ${ }^{(5)}$. Reduz o pH do leito da ferida, estimulando a produção de citocinas que promovem a reprodução celular e tornam o meio desfavorável ao crescimento de microrganismos patogênicos ${ }^{(6)}$.

Embora a papaína seja utilizada no Brasil desde 1983, não há consenso entre os enfermeiros, quanto às indicações do uso da papaína, a forma como deve ser utilizada e o tempo de duração da solução após a diluição $0^{(7)}$.

O enfermeiro desempenha um papel muito importante na avaliação da ferida e diante dos recursos e tecnologias lançados pelas indústrias, torna-se necessário avaliar as melhores opções de coberturas, considerando efetividade e menor custo. A prática clínica baseada em evidências contribui para tomada de decisão, através de evidências científicas que possibilitem recomendações para o uso.

Diante disso, surgiram as seguintes questões norteadoras: Nos trabalhos publicados, quais apresentações da papaína têm sido utilizadas no tratamento de feridas? Que evidências existem sobre as indicações, contra-indicações, a efetividade e a segurança do uso da papaína em feridas?

Considerando a necessidade de mais informação quanto ao uso da papaína e sua efetividade, este estudo propõe buscar evidências científicas que subsidiem a tomada de decisões relativas ao seu uso, tendo como objetivo geral: analisar as evidências científicas encontradas na literatura sobre o uso da papaína no processo de cicatrização de feridas e objetivos específicos: caracterizar os estudos que utilizaram a papaína para o tratamento de feridas; identificar as apresentações da papaína utilizadas para cicatrização de feridas; avaliar as indicações, contra-indicações, efetividade e segurança do uso da papaína em feridas.

\section{MÉTODO}

Trata-se de uma revisão sistemática realizada a partir de levantamento bibliográfico manual e eletrônico, de artigos publicados entre 1987 e 2010, nas seguintes bases de dados: Literatura Latino-Americana e do Caribe em Ciências da Saúde (LILACS); Portal de Evidências com foco na Cochrane (COCHRANE); Índice Bibliográfico Español en Ciencias de la Salud (IBECS); Medical Literature Analysis and Retrieval Sistem on-line (MEDLINE) via Pubmed e Cumulative Index to Nursing and Allied Health Literature (CINAHL); utilizando os seguintes descritores, também como palavra: Carica; Papaína e Cicatrização, além dos Mesh terms na MEDLINE (Carica; Papain e Wound Healing). O teste com o descritor Enfermagem e o Mesh term Nursing evidenciou a perda de alguns artigos importantes, portanto optou-se por não restringir a busca.

Utilizou-se a revisão sistemática, pois permite a apropriação de evidências que contribuem para tomada de decisão. As etapas seguidas para realização da revisão foram: definição do problema clínico e critérios para busca; seleção de bases de dados e descritores; elaboração dos testes de relevância; 
aplicação do Teste de Relevância I aos resumos dos artigos identificados; aplicação do Teste de Relevância II aos artigos na íntegra, ambos realizados por dois pesquisadores e elaboração do quadro de síntese dos $\operatorname{artigos}^{(8)}$.

A busca nas bases de dados e os estudos selecionados foram analisados quanto à pertinência ao tema de pesquisa, desenho do estudo, resultados, indicações, apresentação da papaína e principais conclusões dos autores. Como critérios de inclusão, foram selecionados estudos primários em português, inglês e espanhol, na íntegra on-line ou que pudessem ser acessados manualmente. Foram excluídos estudos que não possuíam o resumo, anais de congresso, estudos in vitro e modelos experimentais animais. Não foram incluídos livros-textos na coleta de dados, porém foram utilizados na análise e na contextualização.

A pesquisa foi realizada entre os dias $13 \mathrm{e}$ 14 de julho de 2011. Foi encontrado um total de 9145 artigos, sendo excluídos 6411 após limitar os estudos em humanos e pelo idioma na MEDLINE e na LILACS, resultando em 2734 estudos. Na MEDLINE, havia o maior número de artigos
(2625 artigos), onde realizou-se o cruzamento com o Mesh Term e como palavra: Wound Healing, com exclusão de 2546 artigos, resultando em 79 artigos, que foram analisados quanto ao título e ao resumo com os artigos das demais bases de dados, sendo analisados um total de 188 artigos, com exclusão de 146 artigos. Após análise dos 42 textos, foram excluídos 15 artigos por não se enquadrarem na temática ou por não atenderem os critérios de inclusão e 10 artigos repetidos, com inclusão de 17 artigos para análise e categorização dos dados.

Para análise das evidências e grau de recomendação da papaína encontradas nos estudos utilizou-se a Escala de Oxford $^{(9)}$ por dois autores, não havendo discordância entre os mesmos.

\section{RESULTADOS}

O quadro abaixo apresenta os 17 artigos encontrados e a caracterização dos estudos, quanto aos autores, ano, procedência, base de dados do estudo, método, indicações, apresentação da papaína, principais conclusões dos autores, nível de evidência e grau de recomendação.

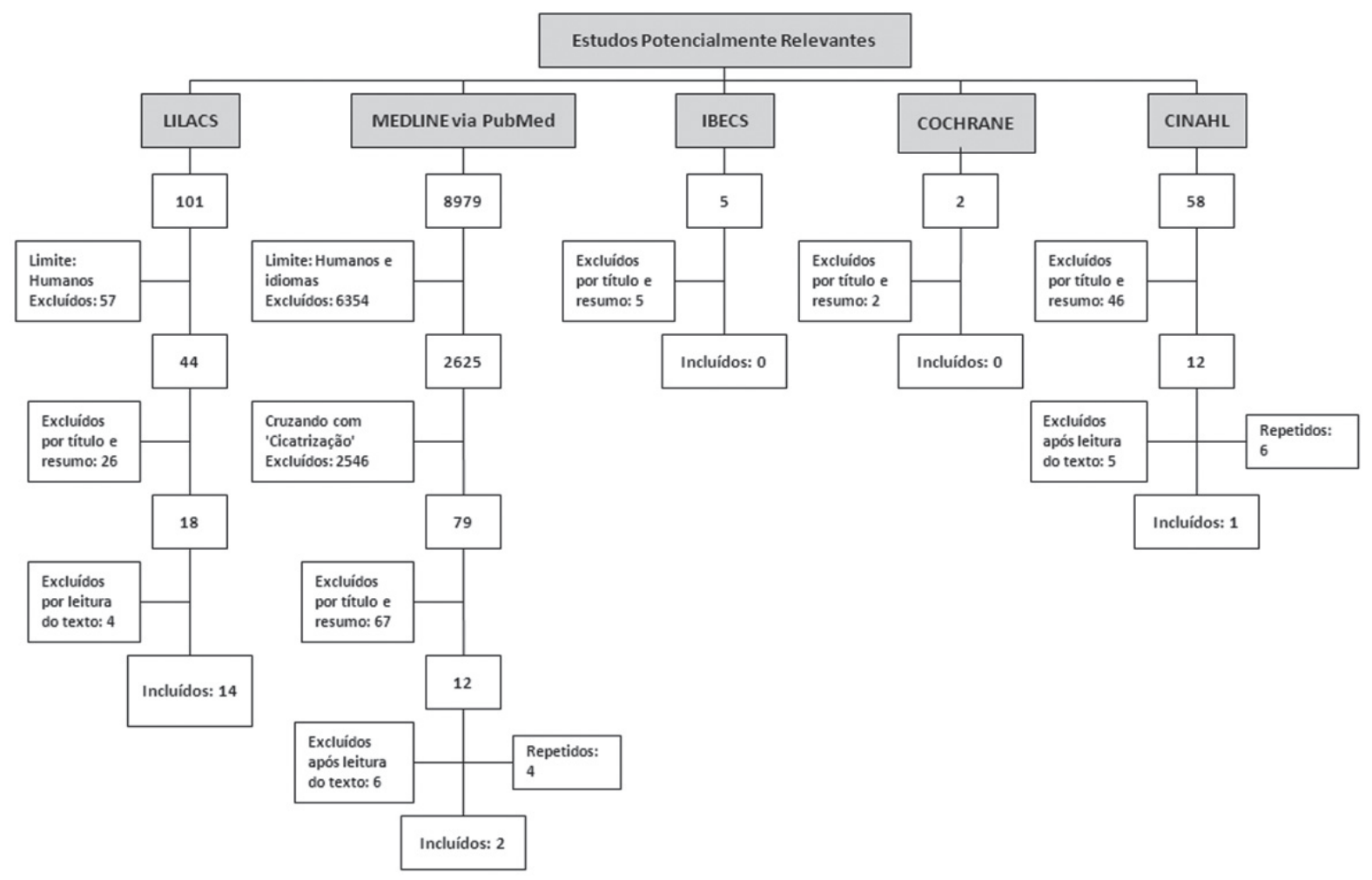

Fluxograma 1 - Fluxo da busca sistemática nas bases de dados. Niterói, RJ, julho 2011. 


\begin{tabular}{|c|c|c|}
\hline $\mathbf{N}^{o}$ & $\begin{array}{l}\text { Autores/Ano/ } \\
\text { Procedência }\end{array}$ & $\begin{array}{c}\text { Tipo de estudo/Indicações/Apresentação da papaína/ } \\
\text { Principais conclusões } \\
\text { Nível de evidência/grau de recomendação }\end{array}$ \\
\hline 01 & $\begin{array}{l}\text { Monetta } \mathrm{L}^{(3)} \\
1987 \\
\text { LILACS }\end{array}$ & $\begin{array}{l}\text { Estudo descritivo. Amostra: } 15 \text { pacientes. } \\
\text { Escara, necrose tecidual por extravasamento de potássio, radiodermite com } \\
\text { linforrafia infectada, furunculose infectada, úlcera com tecido necrosado por } \\
\text { gessos, lesão por fratura exposta de tíbia. } \\
\text { Raspa da polpa do fruto ( } 1 \text { paciente). Papaína em pó (14 pacientes) diluída } \\
\text { em água bidestilada. } \\
\text { Considera a papaína um valioso recurso terapêutico no tratamento de lesões } \\
\text { de pele, de uso seguro pela enfermagem por não oferecer riscos ao paciente, } \\
\text { sendo uma tecnologia apropriada ao Brasil. Estimula novas pesquisas. } \\
\text { 4-C }\end{array}$ \\
\hline $\mathrm{O} 2$ & $\begin{array}{l}\text { Monetta L }{ }^{(10)} \\
1990 \\
\text { LILACS }\end{array}$ & $\begin{array}{l}\text { Estudo descritivo. Amostra: } 52 \text { pacientes. } \\
\text { Politraumatizados, úlceras varicosas, escara, lesão por extravasamento de qui- } \\
\text { mioterápico, pacientes diabéticos insulino-dependentes e transplantados renais. } \\
\text { Papaína em pó diluída em água bidestilada. } \\
\text { Os resultados obtidos em dois anos de pesquisa utilizando a papaína em lesões } \\
\text { de pele com ou sem necrose e até a cicatrização completa justificam seu uso e } \\
\text { ressaltam a importância do enfermeiro conhecer o processo de cicatrização e } \\
\text { fatores intervenientes para intervir de forma reflexiva e científica. } \\
\text { 4-C }\end{array}$ \\
\hline 03 & $\begin{array}{l}\text { Monetta L }{ }^{(11)} \\
1992 \\
\text { LILACS }\end{array}$ & $\begin{array}{l}\text { Estudo descritivo. Amostra: } 18 \text { pacientes. Separados em dois grupos: lesões } \\
\text { infectadas e livres de infeçãa. } \\
\text { Escara, úlceras varicosas, deiscência, antraz, lesão por quimioterapia e lesão } \\
\text { plantar. } \\
\text { Papaína em pó diluída em água bidestilada. } \\
\text { A associação da papaína ao curativo hidrocolóide e ao carvão ativado e prata } \\
\text { mostrou ser efetiva no tratamento das lesões de pele, com erradicação da } \\
\text { infecção e evolução da cicatrização, com um caso de alergia ao hidrocolóide, } \\
\text { com hiperemia, ardor e prurido. A orientação para o uso desses curativos pelo } \\
\text { paciente diminuiu a dependência do profissional de saúde. } \\
\text { 4-C }\end{array}$ \\
\hline 04 & $\begin{array}{l}\text { RogenskiNMB et } \\
\text { al. }{ }^{(12)} \\
1995 \\
\text { LILACS }\end{array}$ & $\begin{array}{l}\text { Estudo de caso. Amostra: } 4 \text { pacientes. } \\
\text { Infecção grave em vísceras. Toracotomia por tuberculose pulmonar, Enfisema } \\
\text { subcutâneo traumático infectado; pós-operatório de laparotomia exploradora } \\
\text { por volvo de sigmóide, com sigmoidectomia e colostomia infectado; Síndrome } \\
\text { de Fournier. } \\
\text { Solução de papaína a } 2 \% \text {, em água bidestilada nas primeiras } 24 \text { horas da Sín- } \\
\text { drome de Fournier, sendo modificada para } 1 \% \text { quando em uso da solução de } \\
\text { irrigação contínua do peritônio, nas lesões externas, foi utilizada a papaína a 4\%. } \\
\text { Amostra pequena. A papaína proporcionou diminuição significativa da quan- } \\
\text { tidade de secreção purulenta após } 48 \text { horas de irrigação contínua, sem efeitos } \\
\text { colaterais, com cicatrização total das regiões afetadas em } 30 \text { dias, evidenciando } \\
\text { uma excelente resposta ao uso da papaína. } \\
4-\text { C }\end{array}$ \\
\hline
\end{tabular}




\begin{tabular}{|c|c|c|}
\hline 05 & $\begin{array}{l}\text { Otuka ES, et al. }{ }^{(13)} \\
1996 \\
\text { LILACS }\end{array}$ & $\begin{array}{l}\text { Descritivo. Amostra: } 3 \text { pacientes. } \\
\text { Úlcera plantar em pacientes com hanseníase. } \\
\text { Solução de papaína em pó (1:750) diluída em água bidestilada. } \\
\text { A papaína proporcionou cicatrização rápida. Técnica simples, pode ser execu- } \\
\text { tada pelo paciente. Melhorou a interação enfermeiro-paciente, possibilitando } \\
\text { a realização de ações educativas. } \\
4-\mathrm{C}\end{array}$ \\
\hline 06 & $\begin{array}{l}\text { Rogenski NMB, } \\
\text { et al. }^{(14)} \\
1998 \\
\text { LILACS }\end{array}$ & $\begin{array}{l}\text { Descritivo. Amostra: } 14 \text { pacientes. } \\
\text { Síndrome de Fournier. } \\
\text { Solução de papaína a } 2 \% \text { em pó diluída em soro fisiológico a } 0,9 \% \text {. } \\
\text { A papaína facilitou a cicatrização, acelerando a recuperação, reduzindo des- } \\
\text { bridamentos cirúrgicos sucessivos. } \\
4-\mathrm{C}\end{array}$ \\
\hline 07 & $\begin{array}{l}\text { Starley IF, et al. }{ }^{(15)} \\
1999 \\
\text { MEDLINE }\end{array}$ & $\begin{array}{l}\text { Relato de casos. Amostra: } 32 \text { pacientes. } \\
\text { Queimaduras profundas, extensas, infectadas. } \\
\text { Pasta da polpa de mamão. } \\
\text { A papaína foi efetiva na queimadura com necrose, limitando a infecção. Esti- } \\
\text { mula novas pesquisas. } \\
\text { 4- C }\end{array}$ \\
\hline 08 & $\begin{array}{l}\text { Prochnow AG, et } \\
\text { al. }{ }^{(16)} \\
2000 \\
\text { LILACS }\end{array}$ & $\begin{array}{l}\text { Estudo exploratório e prospectivo, com tratamento estatístico. Amostra: } 9 \\
\text { pacientes. } \\
\text { Úlceras cutâneas em diabéticos em membros inferiores, úlceras plantares. } \\
\text { Solução de papaína a } 2 \% \text {, em água bidestilada. } \\
\text { Melhora clínica e estatística das lesões. Porém ressaltam fatores intervenien- } \\
\text { tes como tempo de doença, idade, controle metabólico, complicações crônicas } \\
\text { vigentes que podem interferir na cicatrização. } \\
\text { 4-C }\end{array}$ \\
\hline 09 & $\begin{array}{l}\text { Ferreira AM, et } \\
\text { al. }^{(17)} \\
2002 \\
\text { LILACS }\end{array}$ & $\begin{array}{l}\text { Estudo descritivo, exploratório. Amostra: 14 pacientes. } \\
\text { Pacientes com lesões abdominais por deiscência de sutura. } \\
\text { Papaína gel a } 3 \% \text {. } \\
\text { Estimula a avaliação criteriosa da lesão pelo enfermeiro. } \\
4 \text { - C }\end{array}$ \\
\hline 10 & $\begin{array}{l}\text { Alvarez OM, et } \\
\text { al. }^{(18)} \\
2003 \\
\text { CINAHL }\end{array}$ & $\begin{array}{l}\text { Ensaio clínico prospectivo, randomizado, comparativo, tricêntrico, controla- } \\
\text { do, não-cego. Amostra: } 26 \text { pacientes internados, divididos em dois grupos: } \\
\text { Colagenase (n=12), Papaína-ureia }(n=14) \text {. } \\
\text { Úlceras por pressão. } \\
\text { Papaína associada à ureia (creme). } \\
\text { A associação da papaína com a ureia foi mais efetiva que a colagenase na } \\
\text { redução do esfacelo e no aumento do tecido de granulação. } \\
\text { 1B - A }\end{array}$ \\
\hline 11 & $\begin{array}{l}\text { Coutinho VL } \\
2004 \\
\text { LILACS }\end{array}$ & $\begin{array}{l}\text { Estudo exploratório, quantitativo. Amostragem não probabilística acidental, por } \\
\text { ordem de chegada, com tratamento estatístico dos dados. Amostra: } 20 \text { pacientes. } \\
\text { Úlcera venosa, mista, com linfangite e lesões de etiologia traumática e infecciosa. } \\
\text { Papaína associada ao silicato de magnésio. } \\
\text { Pode ser realizado curativo domiciliar pelo paciente por ser prático e fácil. } \\
\text { Recomenda novas pesquisas com maior amostra e rigor metodológico. } \\
4-\mathrm{C}\end{array}$ \\
\hline
\end{tabular}


Continuação.

\begin{tabular}{|c|c|c|}
\hline 12 & $\begin{array}{l}\text { Bueno M, et al. }{ }^{(20)} \\
2005 \\
\text { LILACS }\end{array}$ & $\begin{array}{l}\text { Estudo de caso. Amostra: } 1 \text { paciente. } \\
\text { Recém-nascido com deiscência de sutura em ferida cirúrgica de correção de } \\
\text { mielomeningocele. } \\
\text { Papaína a } 10 \% \text { no leito até o } 11^{\circ} \text { dia de tratamento; papaína a } 1 \% \text { até o } 19^{\circ} \text { dia } \\
\text { de tratamento; papaína a } 0,5 \% \text { até o } 24^{\circ} \text { dia de tratamento. } \\
\text { A papaína atuou adequadamente como desbridante químico, quando aplicada } \\
\text { em concentração elevada, e facilitou o processo cicatricial e de granulação } \\
\text { tecidual em concentrações diminutas. } \\
4-\text { C }\end{array}$ \\
\hline 13 & $\begin{array}{l}\text { Glenn } J^{(21)} \\
2006 \\
\text { MEDLINE }\end{array}$ & $\begin{array}{l}\text { Estudo de caso. Amostra: } 1 \text { paciente. } \\
\text { Ferida traumática em região anterior pélvica, não infectada. } \\
\text { Creme de papaína-ureia-clorofila; adicionado Spray de papaína-ureia na ter- } \\
\text { ceira semana de tratamento. } \\
\text { Conclui que a papaína se mostrou segura e efetiva em idosos, porém mais } \\
\text { pesquisas são recomendadas. } \\
4-\mathrm{C}\end{array}$ \\
\hline 14 & $\begin{array}{l}\text { Salomé GM } \\
2007 \\
\text { LILACS }\end{array}$ & $\begin{array}{l}\text { Estudo de caso: Amostra: } 01 \text { paciente. } \\
\text { Lesão neuropática em paciente com diabetes mellitus. } \\
\text { Papaína em pó } 100 \% \text { e AGE. } \\
\text { Concluiu que a papaína em pó em necrose e esfacelo facilita a cicatrização de } \\
\text { lesão neuropática. Recomenda mais estudos. } \\
4-\mathrm{C}\end{array}$ \\
\hline 15 & $\begin{array}{l}\text { Salomé GM, Ar- } \\
\text { bage CC } \text { (23) }^{2} \\
2008 \\
\text { LILACS }\end{array}$ & $\begin{array}{l}\text { Estudo de caso: Amostra: } 01 \text { paciente. } \\
\text { Úlcera por pressão no calcâneo. } \\
\text { Papaína em pó } 100 \% \text { e } 2 \% \text {. } \\
\text { Concluiu que a papaína pode ser um facilitador na cicatrização da ferida, sem } \\
\text { desbridamento cirúrgico. } \\
4-\text { C }\end{array}$ \\
\hline 16 & $\begin{array}{l}\text { Gonçalves AC, et } \\
\text { al. }{ }^{(24)} \\
2008 \\
\text { LILACS }\end{array}$ & $\begin{array}{l}\text { Estudo de caso: Amostra: } 01 \text { paciente. } \\
\text { Lesão por Piomiosite Tropical em região glútea. } \\
\text { Papaína em gel a 3\%. } \\
\text { A papaína em gel a } 3 \% \text { demonstrou efetividade no desbridamento, propor- } \\
\text { cionou crescimento do tecido de granulação, sem relato de dor, com melhora } \\
\text { da auto-estima e da segurança. } \\
4-\text { C }\end{array}$ \\
\hline 17 & $\begin{array}{l}\text { Rangel EML }{ }^{(25)} \\
2009 \\
\text { LILACS }\end{array}$ & $\begin{array}{l}\text { Estudo transversal, descritivo, com análise quantitativa dos dados. } \\
\text { Úlceras por pressão. } \\
\text { Apresentação não referida. } \\
\text { As práticas utilizadas pelos enfermeiros variaram. Necessária a utilização de } \\
\text { diretrizes baseadas em evidências para o tratamento de úlceras de pressão, } \\
\text { maior divulgação e acesso da equipe de saúde a esse conhecimento. } \\
5 \text {-D }\end{array}$ \\
\hline
\end{tabular}

Quadro 1 - Distribuição e caracterização dos estudos. Niterói, RJ, 2011. 


\section{DISCUSSÃO}

Por meio da análise dos resultados, identifica-se predomínio ( $88 \%$ ) de estudos descritivos, exploratórios, estudos de caso e relatos de caso, sendo encontrado apenas um $(6 \%)$ ensaio clínico randomizado e controlado, outro estudo (6\%) trata da opinião de especialistas. Há predomínio de estudos brasileiros $(82 \%)$, porém foi encontrado um estudo africano $(6 \%)$ e dois americanos (12\%). Os estudos foram analisados nas seguintes categorias:

\section{Categoria 1: Indicações e contra-indicações ao uso da papaína}

A papaína foi utilizada em feridas de diversas etiologias infectadas e limpas (úlceras por pressão, venosas, plantares, diabéticas, por hanseníase, lesões por extravasamento de potássio e quimioterápicos, deiscências de sutura, Síndrome de Fournier e Piomiosite Tropical), sendo considerada desde 1987, um valioso recurso terapêutico, seguro e que não oferece riscos ao paciente ${ }^{(3)}$.

Além disso, foi utilizada nas diversas fases do processo de cicatrização, sendo modificada a concentração do produto. Atualmente, preconiza-se para tecido de granulação, uma concentração de $2 \%$ de papaína; na presença de necrose de liquefação, 4 a $6 \%$ e na necrose de coagulação, 8 a 10\%, após escarectomia ${ }^{(26)}$. Nenhum dos estudos avaliados referiu contra-indicações, porém em três estudos ${ }^{(3,10-11)}$, houve relatos de ardência e dor durante e após a realização do curativo, sendo que não foi especificada a concentração.

A papaína apresenta bons resultados como desbridante e acelerador do processo de cicatrização, com formação de tecido de granulação, com baixo custo em relação a coberturas industrializadas ${ }^{(13-14,18)}$.

\section{Categoria 2: Apresentações da papaína}

Os estudos utilizaram cinco formas de apresentação da papaína: polpa, pó, gel, em creme associado à ureia e/ou clorofila e spray (sendo as duas últimas, formulações não comercializadas no Brasil, apenas em fórmulas manipuladas).

A utilização da papaína ocorreu, a princípio, pela aplicação da polpa de mamão raspada diretamente sobre a ferida, utilizando uma faca plástica esterilizada. O estudo refere ter usado a polpa do mamão em apenas um paciente, pelo receio do risco de infecção, sendo utilizada a forma em pó diluída nos demais pacientes ${ }^{(3)}$. Outro relato do uso da polpa foi de 1999 em queimaduras de crianças na África, devido ao baixo custo e fácil aplicabilidade ${ }^{(15)}$.

Cerca de $60 \%$ dos estudos utilizou a forma em pó, diluída em água bidestilada ou em soro fisiológico. A papaína nessa apresentação consiste em um pó amorfo, levemente higroscópico, branco ou branco acinzentado, solúvel em água, em solução que varia de incolor a amarela clara pouco opaca. É parcialmente solúvel em glicerina. A solução a 2\% possui um $\mathrm{pH}$ de 4,8 a 6,2. Deve ser mantida livre da luz e umidade, em recipiente fechado e refrigera$\mathrm{do}^{(26)}$, com uso imediato para evitar a inativação das propriedades enzimáticas da papaína. Recomenda-se o uso de frascos plásticos, porcelana, vidro, opacos e pequenos ${ }^{(3,10,22)}$ além do uso de luvas, espátulas de madeira e máscara pelo profissional ${ }^{(18)}$. O uso de máscaras é recomendado ao profissional nos casos em que ocorra manipulação da papaína em pó pelo risco de aspiração do produto, que pode causar doenças respiratórias, como enfisema pulmonar ${ }^{(27)}$ evidenciado em estudos experimentais com ratos.

A associação da papaína com outras substâncias exige atenção do enfermeiro porque a papaína é inativada ao reagir com agentes oxidantes como o ferro, o oxigênio, derivados de iodo, água oxigenada e nitrato de prata, luz e calor ${ }^{(5)}$. A fim de conservar a atividade proteolítica da papaína, em três estu$\operatorname{dos}^{(3,10-11)}$ foi evidenciado que sua diluição em pó foi realizada no momento da aplicação e utilizada logo em seguida. Dois estudos referem ter deixado a solução para uso por 12 horas em ar ambiente ${ }^{(13,22)}$. Atualmente, foi demonstrado que essa exposição prolongada causa inativação enzimática do produto com perda da atividade proteolítica ${ }^{(28)}$.

Um estudo (6\%) refere dificuldades do uso da papaína em pó diluída, como: necessidade de treinamento da equipe de enfermagem quanto à manipulação do produto; dificuldades de calcular as concentrações de soluto e solvente para preparo da solução, principalmente pelo paciente. Nesse estudo, a autora optou pelo uso da papaína com silicato de magnésio hidratado em pó, por demandar menor custo e diminuição do tempo gasto do profissional para manipulação. A apresentação da papaína em creme demonstrou resultados insatisfatórios, como maceramento das bordas da ferida, com tecido de granulação friável e amolecido. O silicato de magnésio 
demonstrou não atuar como corpo estranho na ferida, favorecendo a cicatrização $0^{(19)}$.

O uso do gel na concentração a $3 \%$ foi desenvolvido por Velasco em 1993, sendo citado pela primeira vez em $1995^{(14)}$, com registro dos resultados do seu uso em pacientes em 2002 ${ }^{(17)}$. Desde então, o uso do gel tem se tornado uma tendência no Brasil, por facilitar o uso e diminuir a manipulação do pó da papaína, buscando manter por mais tempo a estabilidade da enzima.

De acordo com estudo realizado em São Paulo acerca do uso da papaína, não havia consenso quanto às indicações, tempo de duração da papaína após diluição e armazenamento entre 95\% dos enfermeiros participantes $^{(7)}$, demonstrando a importância e a necessidade de trabalhos que divulguem evidências consistentes do seu uso para embasamento da prática da enfermagem.

\section{Categoria 3: Efetividade e segurança do uso da papaína para cicatrização de feridas}

Todos os estudos referem dados da efetividade da papaína, em diferentes apresentações e concentrações, cinco $(30 \%)$ relatam que a papaína possui efeito bacteriostático, bactericida e antiinflamatório ${ }^{(3,16-17,22-29)}$, porém a avaliação da atividade antibacteriana in vitro de géis com diferentes concentrações de papaína demonstrou que apenas a papaína a 10\% foi capaz de inibir o crescimento do $S$. aureus e de duas cepas de $P$. aeruginosa ${ }^{(29)}$.

Nos estudos avaliados, foi referida a segurança do uso da papaína, apesar de alguns relatos de dor e ardência, que diminuíam gradativamente, durando no máximo, 20 minutos. Apenas um paciente referiu dor intensa com suspensão do tratamento ${ }^{(3,10)}$. Em um estudo não pode ser avaliada a presença de efeitos indesejáveis, por ter sido utilizada em recém-nascido em uso de citrato de fentanila ${ }^{(20)}$. $\mathrm{O}$ contato da pele com a papaína por 24 horas não levou a alterações relevantes, evidenciando que poderia ser seguramente aplicada ${ }^{(30)}$.

No entanto, há registros de alergia ocupacional à papaína, desencadeada por inalação ou por contato, devido à manipulação da papaína tanto em indústrias, como em estabelecimentos estéticos ${ }^{(31-32)}$. Também foi reportado um caso de alergia desencadeada pela ingestão da fruta, sendo que o paciente já havia demonstrado a mesma reação quando exposto ao látex ${ }^{(33)}$. Há relatos de pacientes, nos Estados Unidos, com alergia ao látex, que fizeram reação cruzada com formulações contendo papaína, porém esses registros se restringem a esse país. No Brasil, não há registros de alergias ao látex do papaya ${ }^{(26)}$.

Quanto aos níveis de evidências científicas e graus de recomendação, de acordo com a Escala de Oxford, dos 17 estudos avaliados, apenas um (6\%) foi classificado como de boa qualidade, tendo obtido nível 1B, com grau de recomendação A, 15 estudos $(88 \%)$ apresentaram baixa qualidade, com nível de evidência 3 e grau de recomendação $\mathrm{C}$, e um estudo (6\%) foi realizado com especialistas, tendo nível de evidência $5-\mathrm{D}$.

\section{CONCLUSÃO}

Nesta revisão, constatou-se a efetividade da papaína como desbridante e estimulante do processo de cicatrização de feridas, porém não foi definido um padrão de formas e apresentação para uso do produto. Quanto às indicações, identifica-se que a papaína foi utilizada em feridas de diversas etiologias, nas diferentes fases do processo de cicatrização e em pacientes de diferentes faixas etárias, como recém-nascido, adultos e idosos. Foram identificadas diversas formas de apresentação do produto, como polpa do mamão verde, pó, gel, creme associado à ureia com ou sem clorofila, e spray, demonstrando aperfeiçoamento da tecnologia. Além disso, a papaína demonstrou ser segura e efetiva em todos os estudos, apesar de alguns relatos de dor e ardência.

Quanto à análise das evidências dos artigos encontrados, nota-se uma preocupação dos autores quanto ao desenvolvimento da pesquisa, porém a falta de grupo controle, cegamento e randomização tornam os estudos de baixa qualidade segundo as escalas internacionais de avaliação. A valorização de pesquisas clínicas se pauta na necessidade de evidências que garantam a recomendação do uso de tecnologias que sejam seguras, efetivas e de baixo custo.

Portanto, há necessidade de serem desenvolvidos estudos com maior rigor metodológico, tais como ensaios clínicos controlados randomizados, para avaliar com maior precisão a efetividade da papaína no processo de cicatrização de feridas. Recomendam-se também estudos farmacológicos que analisem o tempo de estabilidade da papaína, a fim de definir o tipo de armazenamento e de uso, contribuindo para melhor assistência de enfermagem ao paciente portador de feridas. 


\section{REFERÊNCIAS}

1 Mandelbaum SH, Di Santis EP, Mandelbaum MHS. Cicatrização: conceitos atuais e recursos auxiliares Parte I. An Bras Dermatol. [Internet]. 2003 [citado 2012 jun 02];78(4):393-410. Disponível em: http:/ / www.scielo.br/pdf/abd/v78n4/16896.pdf

2 Feijó E, Cruz ICF, Lima DVM. Infecção da ferida - revisão sistematizada da literatura. Online Braz J Nurs. [Internet]. 2008[citado 2010 nov 29];7(3). Disponível em: http://www.objnursing.uff.br/index.php/ nursing/article/view/j.1676-4285.2008.1819/433

3 Monetta L. Uso da papaína nos curativos feitos pela enfermagem. Rev Bras Enferm. 1987;40 (1):66-73.

4. Sanchez Neto R, Barone B, Teves DC, Simões MJ, Novo NF, Juliano Y. Aspectos morfológicos e morfométricos da reparaçäo tecidual de feridas cutâneas de ratos com e sem tratamento com soluçäo de papaína a 2 por cento. Acta Cir Bras. 1993;8(1):18-23.

5 Silva LM. Efeitos benéficos da papaína no processo terapêutico de lesões de pele. In: Jorge AS, Dantas SRPE. Abordagem multiprofissional do tratamento de feridas. São Paulo: Atheneu; 2003. p. 123-132.

6 Falanga V. Wound bed preparation and the role of enzymes: a case for multiple actions of therapeutic agents. Wound. 2002;14(2):47-57.

7 Silva CCR, Rogenski NMB. Uso da papaína: conhecimento de enfermeiros em um hospital da cidade de São Paulo. Rev Estima. 2010;8(1):12-17.

8 Pereira AL, Bachion MM. Atualidades em revisão sistemática de literatura, critérios de força e grau de recomendação de evidência. Rev Gaúcha Enferm. 2006;27(4):491-8.

9 Nobre M, Bernardo W. Prática clínica baseada em evidência. Rio de Janeiro: Elsevier; 2006.

10 Monetta L. A importância da atuação científica do enfermeiro na execução dos curativos feitos com papaína. Rev Paul Enferm. 1990;9(3):83-7.

11 Monetta L. A utilização de novos recursos em curativos num consultório de enfermagem. Rev Paul Enferm. 1992;11(1):19-26.

12 Rogenski NMB, Guedes ML, Baptista CMC, Costa LDF. Uso de papaína em infecções de vísceras. Rev Bras Enferm. 1995;48(2):140-3.
13 Otuka ES, Pedrazzani ES, Pioto MP. Uso de papaína na úlcera plantar. Rev Bras Enferm. 1996;49(2):207-14.

14 Rogenski NMB, Baptista CMC, Sofia MH. O uso da papaína a $2 \%$ nas lesões provocadas pela Síndrome de Fournier: a propósito de 14 casos. Rev Paul Enferm. $1998 ; 17(1 / 3): 39-45$.

15 Starley IF, Mohammed P, Schneider G, Bickler SW. The treatment of paediatric burns using topical papaya. Burns. 1999;25(7):636-9.

16 Prochnow AG, Carneiro M, Ethur ABM. Aplicação tópica de papaína em úlceras cutâneas de pessoas com diabetes. Nursing (São Paulo). 2000;3(27):26-29.

17 Ferreira AM, Poletti NAA, Pereira APS, Ribeiro RCHM. O curativo das lesões abdominais por deiscência de sutura. Nursing (São Paulo). 2002;5(53):29-34.

18 Alvarez OM, Fernandez-Obregon A, Rogers RS, Bergamo L, Masso J, Black M. A prospective, randomized, comparative study of collagenase and papain-urea for pressure ulcer debridement. Wounds. 2003;15(4):293-301.

19 Coutinho VL. Interação enfermeira-cliente e utilização de papaína associada ao silicato de magnésio: uma tecnologia de cuidado de feridas [dissertação]. Rio de Janeiro: Faculdade de Enfermagem/UERJ; 2004.

20 Bueno M, Silva CSMR, Alves ACC, Mikaro AP, Pires PV. Atuação do enfermeiro no tratamento de recém-nascido portador de deiscência de sutura em ferida cirúrgica para correção de mielomeningocele. Rev Mineira Enferm. 2005;9(1):02-06.

21 Glenn J. Managing a traumatic wound in a geriatric patient. Ostomy Wound Manage. 2006;52(4):94-8.

22 Salomé GM. O enfermeiro frente ao paciente com lesão neuropática: relato de experiência. Nursing (Säo Paulo). 2007;9(107):171-175.

23 Salomé GM, Arbage CC. A aplicabilidade da papaína no tratamento de úlcera por pressão de calcâneo: relato de experiência. Nursing (São Paulo). 2008;11(123):364-367.

24 Gonçalves AC, Anselmo AM, Simão CMF, Pelegrini A, Poletti NAA, Sabbag AFF. Tratamento de lesão por piomiosite tropical: relato de caso. Nursing (São Paulo) 2008;11(119):166-170. 
25 Rangel EML. Uso das diretrizes para tratamento da úlcera por pressão por enfermeiros de um hospital geral. Rev Eletr Enferm. [Internet]. 2009 [citado 2010 nov 29];11(1):70-77. Disponível em: http:// www.fen.ufg.br/revista/v11/n1/pdf/v11n1a09.pdf

26 Sociedade Brasileira de Enfermagem em Dermatologia/ Sociedade Brasileira de Estomatologia. Pronunciamento quanto ao uso da papaína. [Internet]2010[citado 2010 set 29]. Disponível em: http://www.sobest.org.br/docs/pronunciamento.pdf

27 Fusco LB, Pêgo-Fernandes PM, Xavier AM, Pazetti R, Rivero DHRF, Capelozzi VL, Jatene FB. Modelo experimental de enfisema pulmonar em ratos induzido por papaína. J Pneumol. [Internet] 2002 [citado 2010 nov 29];28(1). Disponível em: <http://www. scielo.br/pdf/jpneu/v28n1/a03v28n1.pdf >

28 Capucho, HC. Desenvolvimento de formulações tópicas contendo papaína para o tratamento de feridas [dissertação]. Ribeirão Preto: Universidade de São Paulo,; 2007.

29 Ferreira AM, Watanabe E, Nascimento AP, Andrade D, Ito IY. Atividade anti-bacteriana in vitro de géis com diferentes concentrações de papaína. Rev Eletr Enferm. [Internet]. 2008[citado 2010 jan 25];10(4):1035-40. Disponível em: http://www.fen. ufg.br/revista/v10/n4/v10n4a 15.htm

30 Lopes OS, Ruas GW, Baby AR, Pinto CASO, Watanabe I, Velasco MVR, Kaneko TM. Avaliação in vitro da segurança de uso da papaína em pele humana: estudo qualitativo por microscopia de luz e eletrônica de transmissão (MET). Rev Bras Ciênc Farm. [Internet]. 2008[citado 2010 jan 25];44(1):151-156. Disponível em: http://www.scielo.br/pdf/rbcf/ v44n 1/a 17v44n1.pdf

31 Soto-Mera MT, López-Rico MR, Filgueira JF, Villamil E, Cidrás R. Occupational allergy to papain. Allergy. 2000;55(10):983-4.

32 Quiñones D, Alonso S, López R, Sánchez I, Rodríguez F, Fernández L, Jerez J. Urticaria de contacto, rinoconjuntivitis y asma bronquial ocupacional por papaína. Allergol Immunopathol. 1999;27(5):273-5.

33 Quarre JP, Lecomte J, Lauwers D, Gilbert P, Thiriaux J. Allergy to latex and papain. J Allergy Clin Immunol. 1995;95(4):922.

\author{
Endereço da autora / Dirección del autor / \\ Author's address \\ Andréa Pinto Leite \\ Rua São João, 25, ap. 515, Centro \\ 24020-040, Niterói, RJ \\ E-mail: andreapintoleite@yahoo.com.br
}

Recebido em: 10.11.2011

Aprovado em: 27.06.2012 